\title{
Higher Expression of Receptor Tyrosine Kinase Axl, and Differential Expression of its Ligand, Gas6, Predict Poor Survival in Lung Adenocarcinoma Patients
}

\author{
Masashi Ishikawa, MD, Makoto Sonobe, MD, PhD, Ei Nakayama, MD, Masashi Kobayashi, MD, Ryutaro Kikuchi, \\ MD, Jiro Kitamura, MD, Naoto Imamura, MD, and Hiroshi Date, MD, PhD
}

Department of Thoracic Surgery, Faculty of Medicine, Kyoto University, Kyoto, Japan

\begin{abstract}
Background. Downstream activation through receptor tyrosine kinases (RTKs) plays important roles in carcinogenesis. In this study, we assessed the clinical involvement of Axl, an RTK, and its ligand, Gas6, in surgically treated lung adenocarcinoma.

Methods. Axl and Gas6 mRNA and protein expression levels were quantified using quantitative real-time polymerase chain reaction and immunohistochemistry, respectively, in completely resected lung adenocarcinoma tissues $(n=88)$ and were evaluated for correlation with clinicopathologic features and patient survival.

Results. Higher expressions of Axl mRNA/protein and Gas6 protein were significantly related to worse clinicopathological features and prognosis (5-year overall survival rates: Axl mRNA low: $72.3 \%$, high: $49.7 \%, P=0.047$; Axl protein low: $77.5 \%$, high: $38.6 \%, P<0.001$; and Gas6 protein low: $70.5 \%$, high: $48 \%, P=0.042)$. On the contrary, higher Gas6 mRNA expression was related to better clinicopathological features and prognosis (5-year overall survival rates: Gas6 mRNA low: $59.2 \%$, high: $81.8 \%, P=0.054)$. Multivariate analysis suggests that high $A x l$ mRNA expression may be an independent factor for poor patient prognosis $(P=0.04)$.

Conclusions. In lung adenocarcinoma, Axl and Gas6 expression levels were associated with tumor advancement and patient survival, thus rendering them as reliable
\end{abstract}

(C) The Author(s) 2012. This article is published with open access at Springerlink.com

First Received: 26 July 2012;

Published Online: 16 December 2012

M. Ishikawa, MD

e-mail: mishi@kuhp.kyoto-u.ac.jp biomarkers and potential targets for treatment of lung adenocarcinoma.

Non-small cell lung cancer (NSCLC) has been the leading cause of cancer-related deaths world-wide, and adenocarcinoma accounts for about half of all NSCLC cases. ${ }^{1,2}$ Recent strategies for cancer treatment have focused on inhibiting oncogenic pathways in specific cancers. Receptor tyrosine kinases (RTKs) are some of the most common classes of molecules investigated for that purpose, and in the treatment of lung adenocarcinoma, disrupting them with small-molecule RTK inhibitors (TKIs) have already provided us with new and preferred treatment options. ${ }^{3,4}$ Unfortunately though, the targeted patient population and therapeutic effects are still limited, thus further investigation on RTKs is vital to provide more therapeutic alternatives.

Recently, the TAM family of RTKs has been reported to regulate various biological processes. ${ }^{5}$ This family consists of Tyro3 and Mer as well as Axl. ${ }^{6}$ Axl has already been reported to be overexpressed in several human cancers. ${ }^{7-11}$ Its natural ligand, Gas6, binds Axl with three- to tenfold higher affinity than Mer and causes Axl phosphorylation, which results in activation of various downstream pathways. $^{12,13}$ Thus, Axl/Gas6 signaling contributes to a variety of oncogenic mechanisms. ${ }^{14,15}$

Although some reports have already mentioned the expression or effects of Axl in lung cancer, specific or detailed clinical impact of both Axl and Gas6 expression have not, thus far, been fully investigated. ${ }^{16,17}$

In this study, we retrospectively evaluated Axl and Gas6 expression levels in lung adenocarcinoma at both the genetic and protein levels, confirming their role in carcinogenesis, which we believe will be useful clinical reference in utilizing these molecules as cancer biomarkers and future therapeutic targets for the treatment of lung cancer. 


\section{MATERIALS AND METHODS}

\section{Patients, Tissue Samples, and Tumor Information}

Tissue samples were obtained from patients who had undergone complete surgical resection of primary lung adenocarcinoma without any prior anticancer therapies at Kyoto University Hospital between 2001 and 2005 $(n=88)$. All of these tumors were histologically confirmed as lung adenocarcinoma, and their lymph node (LN) metastatic status, pathological (p-) staging, degree of differentiation, and pleural/vascular/lymphatic invasion status were all assessed by board-certified pathologists in the Department of Pathology of Kyoto University Hospital. P-stage was determined by the latest tumor-node-metastasis classification system. ${ }^{18}$ Histological type and grade of cell differentiation were determined according to the WHO classification system. ${ }^{19}$ EGFR gene mutations (exons 18-21) were detected using polymerase chain reaction (PCR) single-strand conformational polymorphism analysis, and $K$-ras gene mutations (codon 12 ) were screened using the mutagenic PCR restriction enzyme fragment length polymorphism method. ${ }^{20}$ Informed consent for participation in this study was obtained from all patients before their surgeries, and this study was reviewed and approved by the Ethics Committee of the Graduate School and Faculty of Medicine at Kyoto University.

\section{Preparation of Tissue mRNA}

For sample collection, tumor tissue samples were dissected immediately after surgical resection and soaked in RNAlater TissueProtect Tubes (Qiagen, Tokyo, Japan) for more than $48 \mathrm{~h}$ before storage at $-80{ }^{\circ} \mathrm{C}$ until use. Total RNA was isolated from tissue samples using RNeasy Plus Mini Kit (Qiagen), and reverse transcription of total RNA was conducted using the Ready-To-Go You-Prime FirstStrand Beads (Amersham Biosciences, Uppsala, Sweden) to obtain cDNA.

\section{Quantification and Evaluation of Axl and Gas6 mRNA}

To quantify Axl and Gas6 mRNA expression levels of each sample, quantitative real-time PCR was performed using the LightCycler thermal cycler system (Roche Diagnostics Japan, Tokyo, Japan). The PCR primers used for the quantitative amplification of $A x l$ mRNA were forward: 5'-GGTGGCTGT GAAGACGATGA-3' and reverse: 5'-CTCAGATACTC CATGCCACT- $3^{\prime}$, and those of Gas6 mRNA were forward: $5^{\prime}$-ACATCTTGCCGTGCGTGCCCTTCA- $3^{\prime}$ and reverse: $5^{\prime}$-ATTCCGCGCCAGCTCCTCAACAGA- ${ }^{\prime}$. The primers for glyceraldehyde-3-phosphate dehydrogenase (GAPDH)
mRNA, used as an internal control, were forward: $5^{\prime}$-ACAACAGCCTCAAGATCATCAG- $3^{\prime}$ and reverse: $5^{\prime}$-TCTTCT GGGTGGCAGTGATG- ${ }^{\prime}$. After a $20-\mu \mathrm{L}$ reaction mixture containing $0.5 \mu \mathrm{M}$ forward and reverse primers and $0.03 \mu \mathrm{g}$ cDNA in QuantiTect SYBR Green PCR Master Mix (Qiagen) was prepared, PCR amplification was initiated by preincubation for $15 \mathrm{~min}$ at $95{ }^{\circ} \mathrm{C}$ for initial activation, followed by 40 cycles of the following protocol: denaturation at $94{ }^{\circ} \mathrm{C}$ for $15 \mathrm{~s}(\mathrm{sec})$, annealing at $59{ }^{\circ} \mathrm{C}$ for $15 \mathrm{~s}$, and elongation at $72{ }^{\circ} \mathrm{C}$ for $15 \mathrm{~s}$ with detection of fluorescence products. The quantitative data were analyzed with LightCycler analysis software version 5.03 (Roche Diagnostics Japan). The expression levels of $A x l$ and $G a s 6$ were represented as the ratio of Axl or Gas6 mRNA value to GAPDH mRNA value. The patients were dichotomized on the basis of the mean value of $A x l$ or Gas6 mRNA expression, and their clinicopathologic features and survival curves were later analyzed.

\section{Immunohistochemistry of Axl and Gas6}

Immunohistochemical (IHC) staining was performed using Dako LSAB + System-HRP (Dako Japan, Tokyo, Japan). Formalin-fixed, paraffin-embedded tissue was cut into $4-\mu \mathrm{m}$ sections and mounted on glass slides. After deparaffinization and rehydration, the slides were heated in a buffer solution (HistoVT One, Nacalai Tesque, Kyoto, Japan) for antigen retrieval at $90{ }^{\circ} \mathrm{C}$ for $20 \mathrm{~min}$. After quenching the endogenous activity with $0.3 \%$ hydrogen peroxide (in absolute methanol) for $10 \mathrm{~min}$, the sections were treated with blocking agent (DAKOCytomation Protein Block, Dako Japan) for 30 min to block nonspecific staining. The sections were incubated overnight with a rabbit anti-Axl polyclonal antibody (sc-20741, 1:100, Santa Cruz Biotechnology, Inc., CA, USA) or a goat anti-human polyclonal Gas6 antibody (AF885, 1:100, R\&D Systems Inc., MN, USA). The slides were then incubated for $50 \mathrm{~min}$ each with the secondary antibody (Biotinylated Link, Dako Japan) and peroxidase (STREPTOAVIDIN-HRP, Dako Japan), followed by visualization with $3,3^{\prime}$-diaminobenzine tetrahydrochloride (DAB + CHROMOGEN, Dako Japan). Finally, the sections were counterstained with Mayer's hematoxylin (Dako REAL Hematoxylin, Dako Japan). The negative control slides were prepared by replacing the primary antibody with an irrelevant mouse immunoglobulin G (N1698, Dako Japan).

\section{Evaluation of IHC Results}

Axl and Gas6 protein expression were estimated according to a semiquantitative scoring system, in which the staining intensity was graded as 0 (no staining), 1 (weak), 2 (moderate), or 3 (strong), and percentage of positive cells was graded as 0 (negative), $1(\leq 10 \%), 2$ 
Axl/Gas6 in Lung Adenocarcinoma

S469

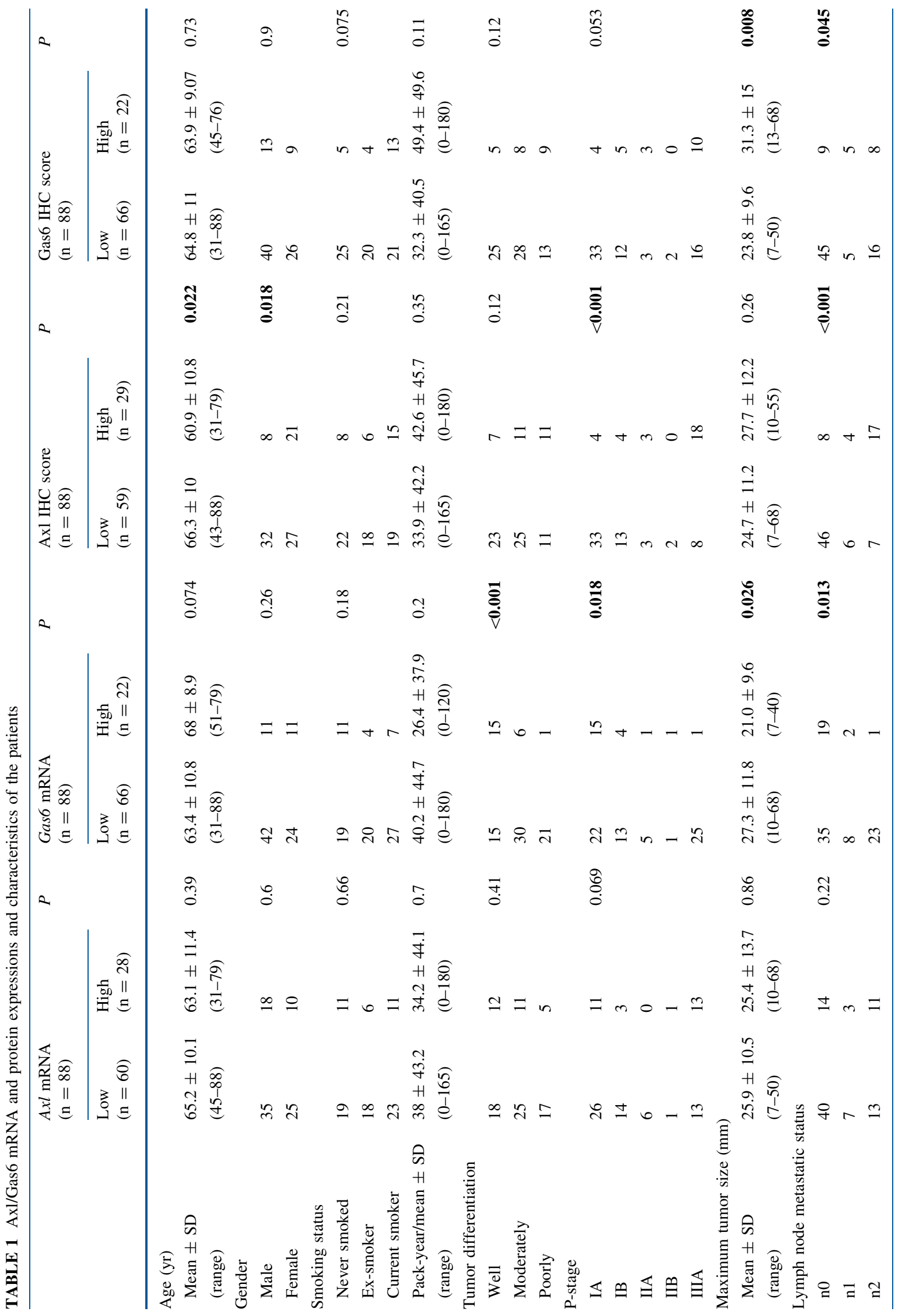


S470

M. Ishikawa et al.

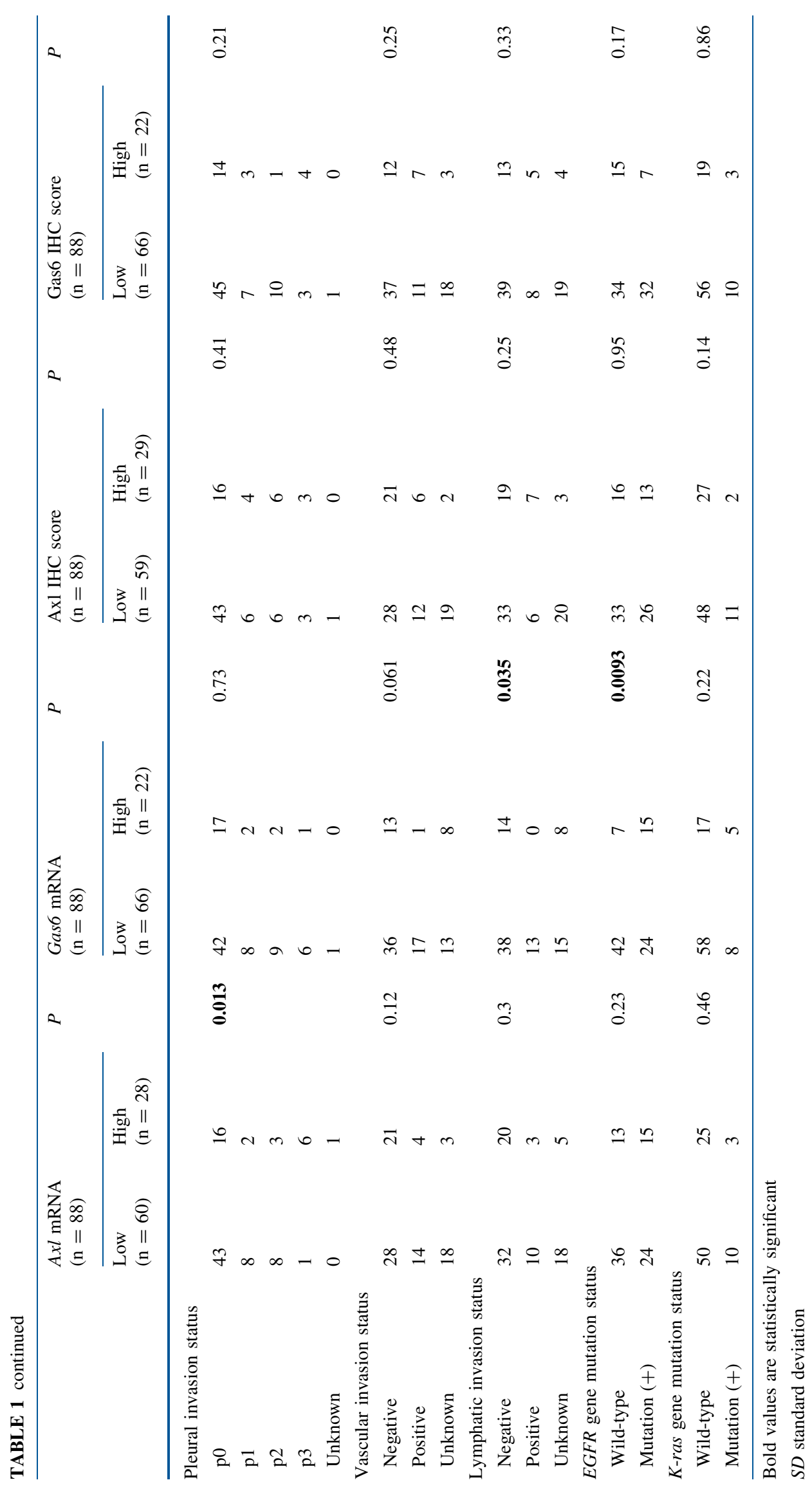


FIG. 1 High $A x l$ mRNA and low Gas6 mRNA expressions in lung adenocarcinoma tissue correlated with poorer patient survival. Kaplan-Meier curves for overall $(\mathbf{a}, \mathbf{c})$ and diseasefree $(\mathbf{b}, \mathbf{d})$ survivals according to $A x l(\mathbf{a}, \mathbf{b})$ and Gas6 (c, d) mRNA expression levels. $P$ values were calculated by the log-rank test. Ticks censored cases a

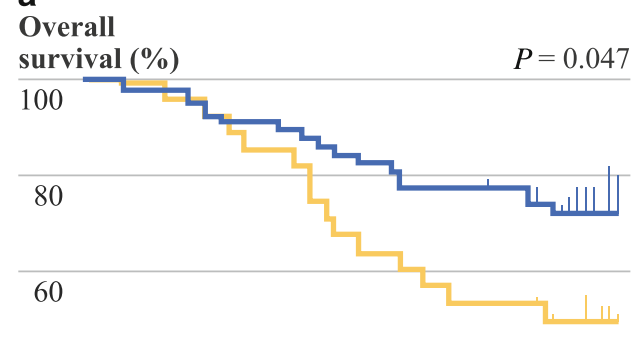

40

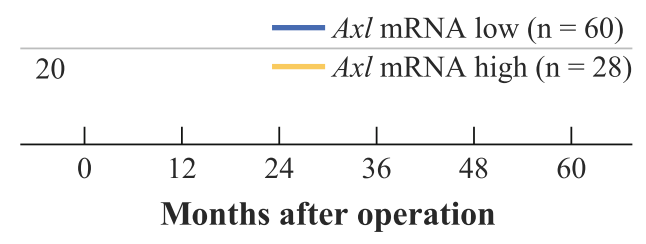

C
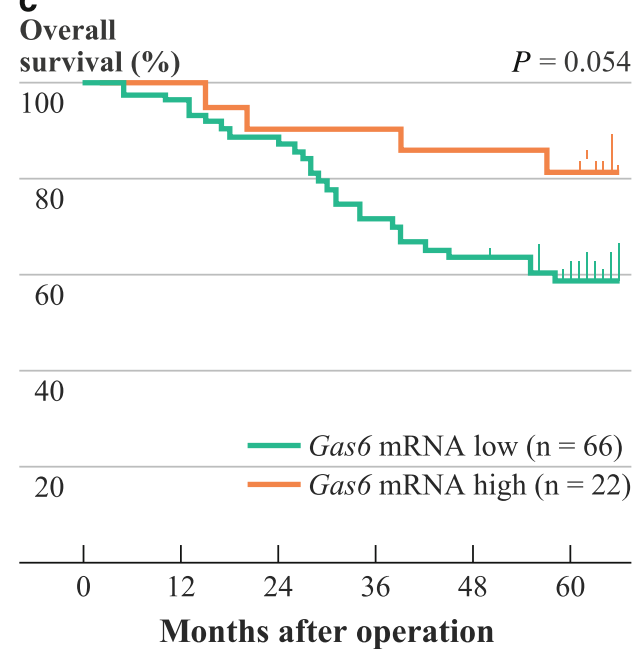

b

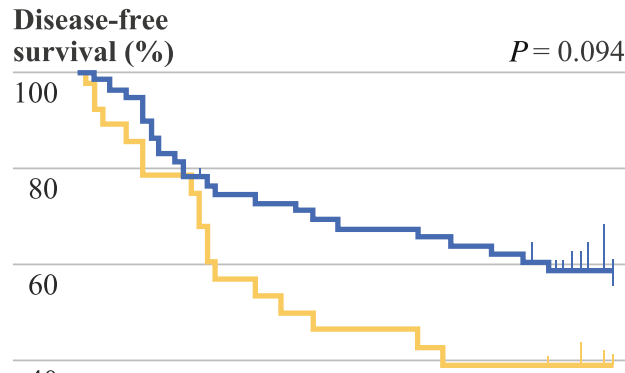

40

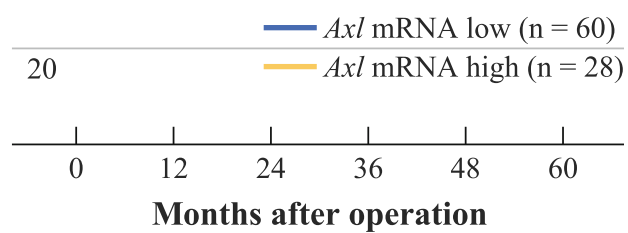

d

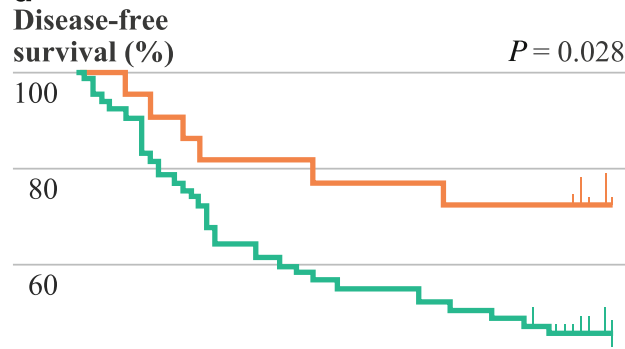

40
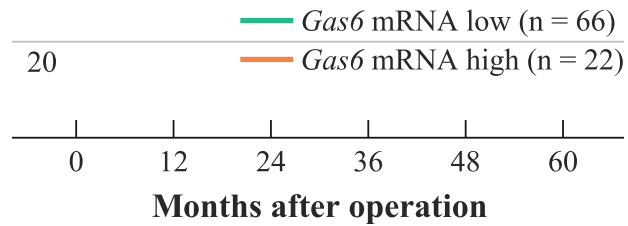

(11-50\%), $3(51-80 \%)$, or $4(>80 \%)$. The final IHC score was obtained by multiplication of both grading results (staining intensity $\times$ percentage of positive cells). The IHC scores were compared within each clinical category, and the clinicopathological features and survival curves were analyzed after dichotomization according to their staining intensity (each IHC score: $\leq 7$ vs. $>7$ ).

\section{Statistical Analysis}

Statistically significant differences within categorical data were determined using the $\chi^{2}$ test. Continuous data of two groups were compared using Student's $t$ test and that of three or more groups were compared using ANOVA. Survival curves were evaluated with the Kaplan-Meier method, and cumulative survival data were compared using the log-rank test. Multivariate analysis of prognostic factors was performed by the Cox proportional hazard model. Differences were considered significant when $P<0.05$. mRNA expression levels and IHC scores are expressed as median and mean \pm standard deviation. All statistical analyses were performed using StatMate IV software version 4.01 (ATMS, Tokyo, Japan) and JMP software version 8 (SAS Institute Japan, Tokyo, Japan).

\section{RESULTS}

\section{Axl and Gas6 mRNA Expression Correlated well with Clinical Variables}

The level of $A x l$ mRNA (normalized and expressed as a ratio to $G A P D H$ mRNA) ranged from 0 to $8.77 \times 10^{-3}$ $\left(8.37 \times 10^{-4}, 1.39 \times 10^{-3} \pm 1.62 \times 10^{-3}\right)$, and that of Gas6 mRNA ranged from $1.26 \times 10^{-4}$ to $2.11 \times 10^{-1}$ $\left(7.59 \times 10^{-3}, 1.37 \times 10^{-2} \pm 2.68 \times 10^{-2}\right)$. Sixty patients were placed in the $A x l$ mRNA low group and 28 patients in the high group, whereas 66 patients were placed in the Gas6 mRNA low group and 22 patients in the high group (below versus above each mean value; Table 1). 
FIG. 2 a Immunohistochemical staining analysis of lung adenocarcinoma tissue for Axl (top) and Gas6 (bottom), showing cases with negative, weak, moderate, and strong staining patterns. Scale bar $20 \mu \mathrm{m}$. b Axl immunoreactivity increased according to tumor differentiation, pathological (p-) stage, maximum tumor size, lymph node (LN) metastatic status, and serum tumor marker levels in lung adenocarcinoma tissue at time of resection. c Gas6 immunoreactivity also correlated well with $\mathrm{LN}$ metastatic status. CEA

carcinoembryonic antigen; $S L X$ sialyl Lewis $\mathrm{X}$-i antigen. $P$ values were calculated by Student's $t$ test or ANOVA a

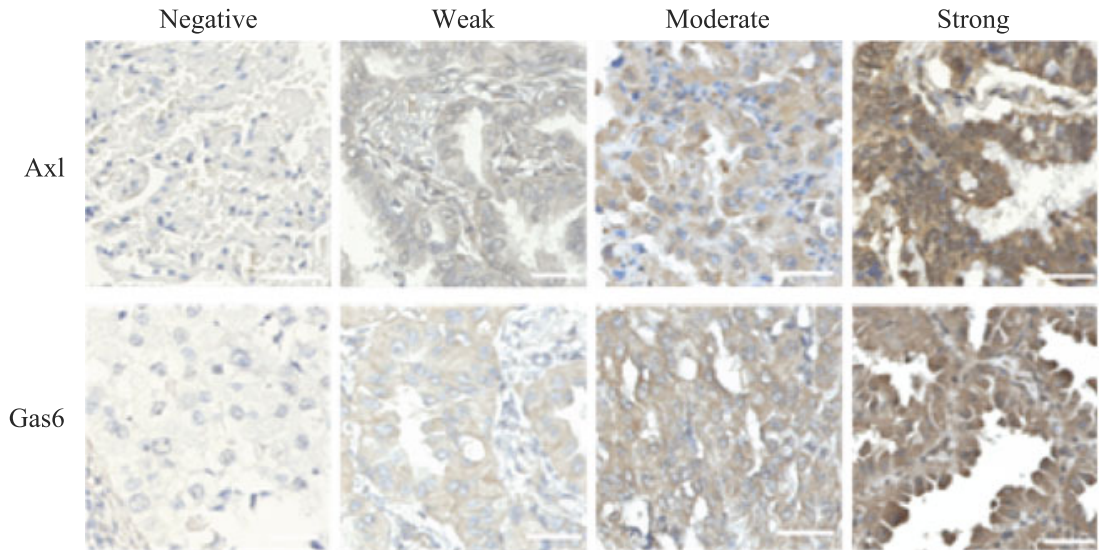

b
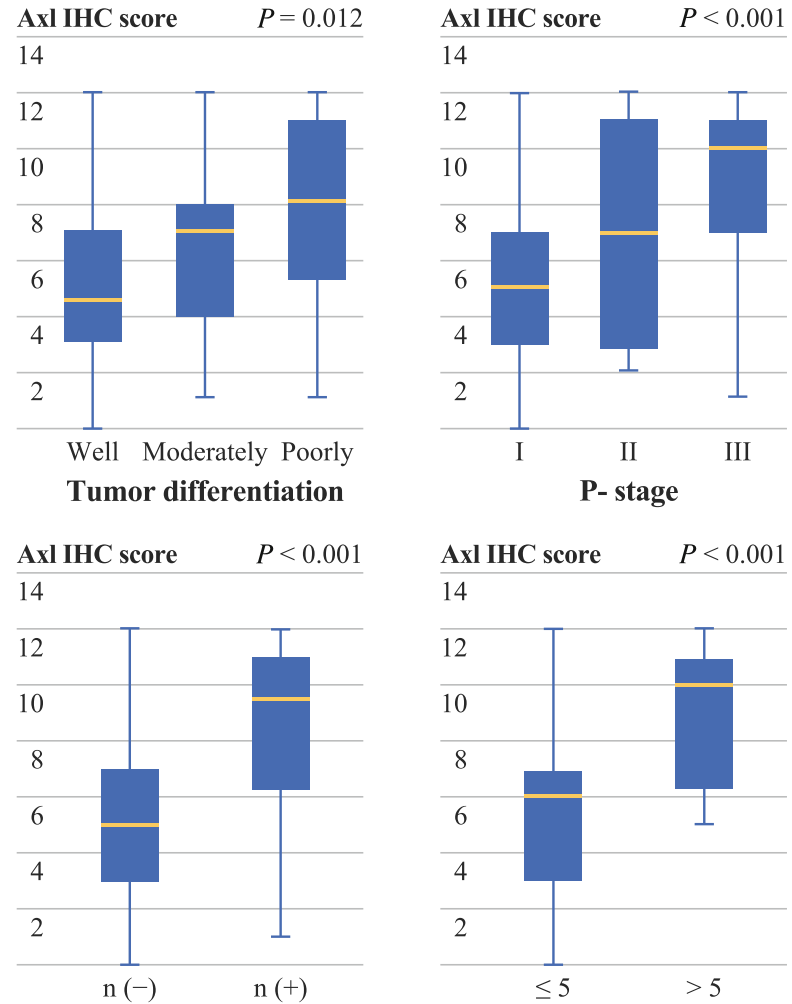

LN metastatic status

C

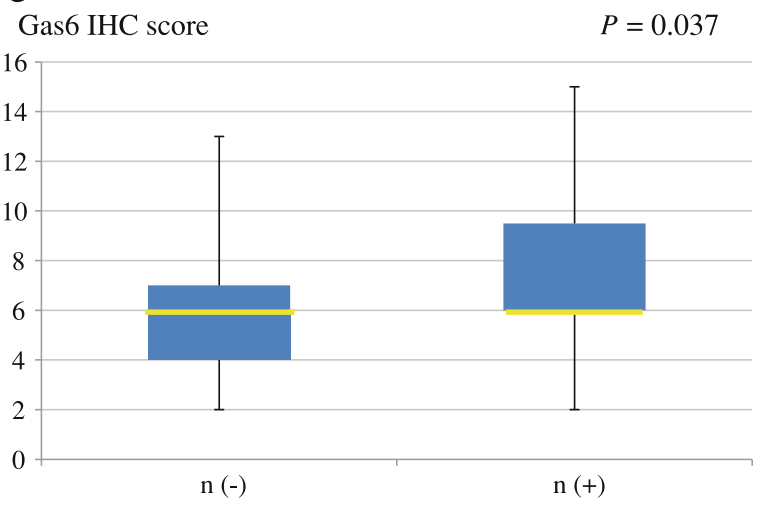

LN metastatic status
Axl IHC score $\quad P=0.028$

14

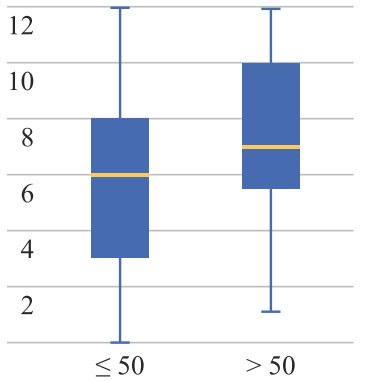

Maximum tumor size (mm)

Axl IHC score $\quad P<0.001$

14

Axl IHC score $\quad P=0.018$

14

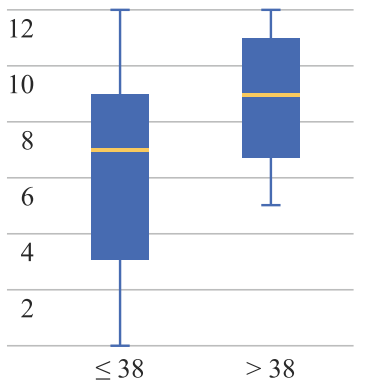

Serum SLX level (U/mL)

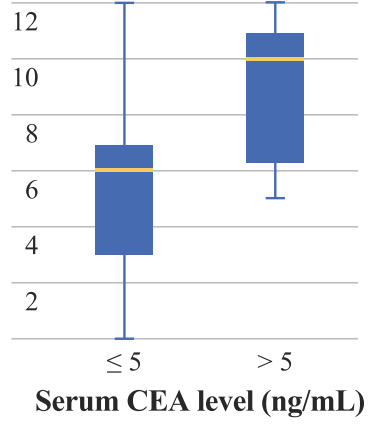


FIG. 3 High Axl and Gas6 immunoreactivity in lung adenocarcinoma tissue predicted poorer patient survival. Kaplan-Meier curves for overall $(\mathbf{a}, \mathbf{c})$ and diseasefree $(\mathbf{b}, \mathbf{d})$ survivals according to Axl (a, b) and Gas6 (c, d) immunohistochemical (IHC) scores. $P$ values were calculated by the log-rank test. Ticks censored cases

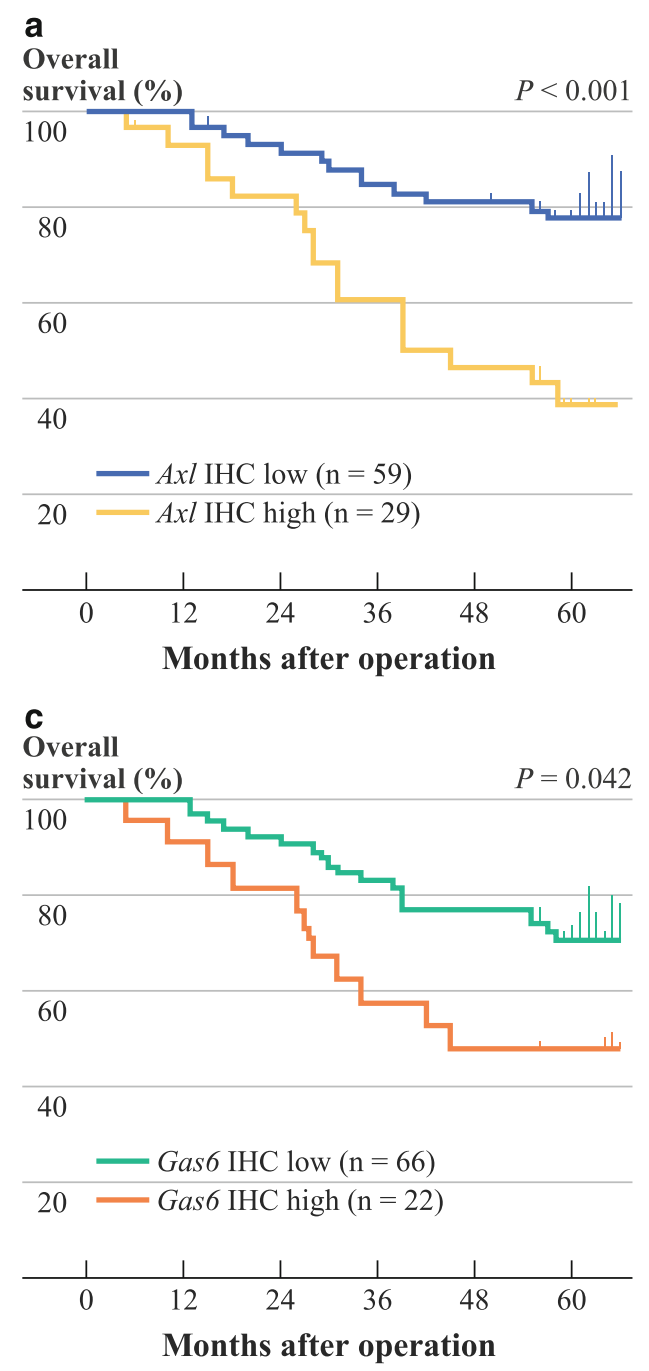

\section{b}

Disease-free

survival $(\%)$

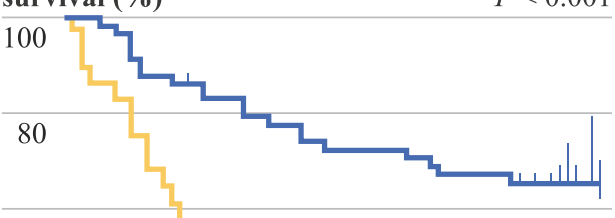

60

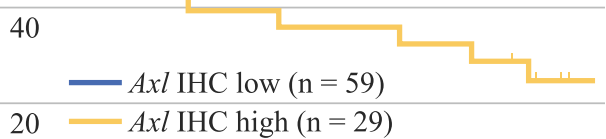

$20=A x l$ IHC high $(\mathrm{n}=29)$

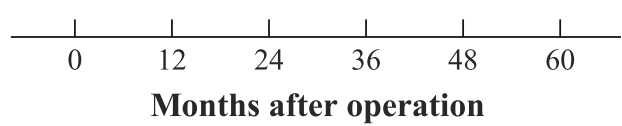

d

Disease-free

survival (\%) $\quad P=0.035$

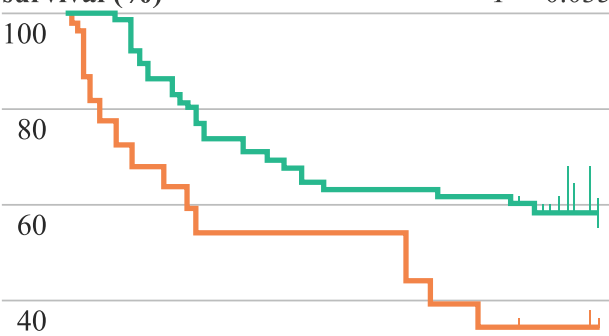

40

- Gas6 IHC low $(\mathrm{n}=66)$
$20=$ Gas6 IHC high $(\mathrm{n}=22)$

\begin{tabular}{cccccc}
$\mid$ & $\mid$ & $\mid$ & $\mid$ & $\mid$ & $\mid$ \\
\hline 0 & 12 & 24 & 36 & 48 & 60 \\
& Months after operation
\end{tabular}
A statistically significant correlation was found between pleural invasion status and Axl mRNA expression. Gas6 mRNA expression was significantly associated with tumor differentiation, p-stage, maximum tumor size, LN metastatic status, lymphatic invasion status, and EGFR gene mutation status, which unexpectedly showed that the high Gas6 mRNA expression group included more patients with better clinicopathological features.

\section{Axl and Gas6 mRNA Expression Reflected Postoperative Patient Survival}

Five-year overall survival (5y-OS) rates in the $A x l$ mRNA low and high groups were 72.3 and $49.7 \%$, respectively, which was statistically significant $(P=0.047$; hazard ratio $(\mathrm{HR})=0.5 ; 95 \%$ confidence interval (CI), 0.21-0.99; Fig. 1a). Five-year, disease-free survival (5y-DFS) rates in the Axl mRNA low and high groups were $58.9 \%$ and $39.3 \%$, respectively $(P=0.094$; Fig. 1b).
Similarly, the 5y-OS rates in the Gas6 mRNA low and high groups were 59.2 and $81.8 \%$, respectively $(P=0.054$; Fig. 1c). The 5y-DFS rates in the Gas6 mRNA low and high groups were statistically different at 45.5 and $72.7 \%$, respectively, and surprisingly, log-rank testing revealed significantly better patient DFS in the Gas6 mRNA high group $(P=0.028 ; \mathrm{HR}=2.5 ; 95 \% \mathrm{CI}$, 1.1-5.7; Fig. 1d).

\section{Axl and Gas6 Protein Expression also Correlated well with Clinical Variables}

The IHC score for Axl ranged from 0 to 12 (7, $6.3 \pm 3.3)$ and that of Gas6 ranged from 2 to 15 (6, $6.3 \pm 2.8$ ). Representative images of Axl and Gas6 IHC at each staining intensity level are presented in Fig. 2a. Statistically significant associations were found between Axl IHC score and tumor differentiation, p-stage, maximum tumor size, LN metastatic status, and serum tumor 
marker levels (Fig. 2b), as well as between Gas6 IHC score and LN metastatic status (Fig. 2c).

Fifty-nine and 29 patients were placed in the Axl IHC low and high groups, respectively, whereas 66 and 22 patients were included in the Gas6 IHC low and high groups, respectively (each $\mathrm{IHC}$ score: $\leq 7$ vs. $>7$; Table 1).

Statistically significant differences were found between the Axl IHC low and high groups with regard to age, gender, p-stage, and LN metastatic status, and between the Gas6 IHC low and high groups with respect to maximum tumor size and $\mathrm{LN}$ metastatic status.

\section{Axl and Gas6 Protein Expression Predicted Patient Survival}

The 5y-OS rates in the Axl IHC low and high groups were 77.5 and $38.6 \%$, respectively, which is statistically significant $(P<0.001 ; \mathrm{HR}=0.31 ; 95 \% \mathrm{CI}, 0.11-0.54$; Fig. 3a). There also was a statistical difference in the 5y-DFS rates between the Axl IHC low and high groups at 65.7 and $24.7 \%$, respectively $(P<0.001 ; \mathrm{HR}=0.33$; $95 \%$ CI, 0.12-0.49; Fig. 3b).

Similarly, the 5y-OS rates in the Gas6 IHC low and high groups were 70.5 and $48 \%$, respectively $(P=0.042$;

TABLE 2 Univariate and multivariate analyses of Axl mRNA expression and other clinicopathological variables for patient survival

\begin{tabular}{|c|c|c|c|c|c|c|c|c|c|}
\hline \multirow[t]{2}{*}{ Variables } & \multicolumn{3}{|c|}{ Univariate analysis (OS) } & \multicolumn{3}{|c|}{ Univariate analysis (DFS) } & \multicolumn{3}{|c|}{ Multivariate analysis (OS) } \\
\hline & Hazard ratio & $95 \% \mathrm{CI}$ & $P^{*}$ & Hazard ratio & $95 \% \mathrm{CI}$ & $P^{*}$ & Hazard ratio & $95 \% \mathrm{CI}$ & $P^{\dagger}$ \\
\hline \multicolumn{10}{|l|}{ Axl mRNA expression } \\
\hline Low & 1 & & 0.047 & 1 & & 0.094 & 1 & & 0.04 \\
\hline High & 2 & $1.01-4.8$ & & 1.7 & $0.91-3.5$ & & 1.9 & $1.03-3.5$ & \\
\hline \multicolumn{10}{|l|}{ Age (yr) } \\
\hline$<65$ & 1 & & 0.47 & 1 & & 0.75 & 1 & & 0.2 \\
\hline$\geq 65$ & 0.77 & $0.38-1.6$ & & 0.91 & $0.5-1.7$ & & 0.71 & $0.43-1.2$ & \\
\hline \multicolumn{10}{|l|}{ Gender } \\
\hline Male & 1 & & 0.0045 & 1 & & 0.087 & 1 & & 0.99 \\
\hline Female & 0.3 & $0.17-0.73$ & & 0.57 & $0.32-1.08$ & & 1 & $0.43-2.1$ & \\
\hline \multicolumn{10}{|l|}{ Smoking status } \\
\hline Never smoked & 1 & & 0.0026 & 1 & & 0.051 & 1 & & 0.37 \\
\hline Smoker (ex or current) & 4.3 & $1.5-6.4$ & & 2 & $1-3.5$ & & 0.68 & $0.28-1.6$ & \\
\hline \multicolumn{10}{|l|}{ Tumor differentiation } \\
\hline Well & 1 & & & 1 & & & 1 & & \\
\hline Moderately & 4.5 & $1.4-9.8$ & 0.01 & 2.6 & $1.2-5.2$ & 0.012 & 1.3 & $0.73-2.2$ & 0.39 \\
\hline Poorly & 11.8 & $5-38.7$ & $<\mathbf{0 . 0 0 1}$ & 4 & $2-11.8$ & $<\mathbf{0 . 0 0 1}$ & 3 & $1.4-6.4$ & 0.004 \\
\hline \multicolumn{10}{|l|}{ P-stage } \\
\hline I & 1 & & & 1 & & & 1 & & \\
\hline II & 0.55 & $0.12-3.1$ & 0.56 & 1.3 & $0.41-4.6$ & 0.6 & 0.63 & $0.22-1.5$ & 0.33 \\
\hline III & 5.9 & $4.6-26$ & $<\mathbf{0 . 0 0 1}$ & 5.3 & $5.3-26.7$ & $<\mathbf{0 . 0 0 1}$ & 2.1 & $1.1-4.1$ & 0.022 \\
\hline \multicolumn{10}{|l|}{ Adjuvant chemotherapy } \\
\hline No & 1 & & & 1 & & & 1 & & \\
\hline Yes & 0.51 & $0.2-1.04$ & 0.061 & 0.62 & $0.29-1.2$ & 0.14 & 0.45 & $0.25-0.8$ & 0.0067 \\
\hline \multicolumn{10}{|l|}{$E G F R$ gene mutation status } \\
\hline Wild-type & 1 & & 0.0077 & 1 & & 0.29 & 1 & & 1 \\
\hline Mutation (+) & 0.35 & $0.19-0.77$ & & 0.72 & $0.39-1.3$ & & 1 & $0.54-1.9$ & \\
\hline \multicolumn{10}{|l|}{$K$-ras gene mutation status } \\
\hline Wild-type & 1 & & 0.23 & 1 & & 0.12 & 1 & & 0.63 \\
\hline Mutation (+) & 0.49 & $0.23-1.4$ & & 0.46 & $0.25-1.2$ & & 1.2 & $0.55-2.6$ & \\
\hline
\end{tabular}

Bold values are statistically significant

$O S$ overall survival; DFS disease-free survival; $C I$ confidence interval

* Log-rank test

${ }^{\dagger}$ Cox’s proportional hazard model 
$\mathrm{HR}=0.48 ; 95 \%$ CI, 0.17-0.97; Fig. 3c). The 5y-DFS rates in the Gas6 IHC low and high groups were 58.4 and $34.5 \%$, respectively, with statistical significance as well $(P=0.035 ; \mathrm{HR}=0.53 ; 95 \%$ CI, 0.21-0.95; Fig. 3d $)$.

\section{High Axl mRNA Expression may be an Independent Factor of Poor Prognosis in Surgically Treated Lung Adenocarcinomas}

The results of the univariate analyses for each clinicopathological parameter and the multivariate analyses are presented in Table 2. We found that high Axl mRNA expression may be an independent factor for poor patient prognosis in lung adenocarcinoma $(P=0.04$; $\mathrm{HR}=1.9$; $95 \%$ CI, 1.03-3.5).

\section{DISCUSSION}

In a previous report, Wimmel et al. ${ }^{16}$ analyzed Axl and Gas6 expression in NSCLC and small cell lung cancer (SCLC) cell lines, and Shieh et al. ${ }^{17}$ reported correlations of Axl protein expression with LN involvement and clinical stage. Our findings on the impact of Axl expression on patient survival further corroborated these observations. Furthermore, our study is the first to identify Axl mRNA expression as a possible independent factor on clinical outcomes in lung adenocarcinoma.

In this report, we found that pleural invasiveness was specifically related to higher $A x l$ mRNA expression, suggesting its pivotal role in tumor invasion, as revealed by Tai et al. ${ }^{21}$ Factors, such as p-stage and LN metastatic status, also were shown to be statistically associated with Axl protein expression, which is consistent with its essential role in epithelial-to-mesenchymal transition. ${ }^{22}$ The independency of EGFR gene mutation in relation to Axl expression also was revealed, which is surprising considering the possible cross-talk or alternative activation between Axl and EGFR. ${ }^{23,24}$ K-ras gene mutation, which is another important mutational pattern in NSCLC, also was found not to be correlated with either Axl or Gas6 expression level. ${ }^{25}$ Higher tumor Gas6 protein expression was shown to be related to not only advanced tumor status but poorer patient survival, suggesting its significance in tumor advancement. ${ }^{11}$

In contrast to these results, it was intriguingly shown that genetic expression of Gas6 had an opposite tendency than that of Axl and Gas6 protein expression. Irrespective of the fact that Gas6-dependent Axl phosphorylation results in subsequent activation of oncogenic pathways, ${ }^{26}$ Cormack et al. ${ }^{27}$ revealed that increased Gas 6 mRNA expression was associated with favorable prognostic factors in breast cancer, and this phenomenon was also found in $\mathrm{RCC} .{ }^{10}$ All of these aforementioned results seen in other types of tumors are concordant with the findings of our present study. Although the precise mechanism underlying this expression inconsistency has yet to be elucidated, it is postulated that while Gas6 mRNA is naturally of tumor origin, Gas6 protein as detected by IHC is generally exogenous. It is already known that Gas6 is expressed not only by tumor cells but also by endothelial cells, fibroblasts, vascular smooth muscle cells, and infiltrating immune cells, ${ }^{28}$ and tumor cells are stimulated via paracrine as well as autocrine fashion by Gas6, which also is found in serum. ${ }^{10}$ It also is assumed that paracrine-derived Gas6 incorporation into tumor cells represses tumoral Gas6 expression per se, resulting in downregulation of Gas6 mRNA expression. We hope that further investigations will clarify the underlying mechanisms.

In light of the limited therapeutic options currently available for NSCLC, the Axl/Gas6 system remains an attractive therapeutic target, ${ }^{29}$ and some small molecules with Axl inhibitory effects are already under development. ${ }^{30}$ Elucidation of the exact mechanisms of Gas6 stimulation on tumor tissue (i.e., autocrine and/or paracrine) would increase the efficacy of targeting this RTK axis for the treatment of lung adenocarcinoma.

In conclusion, we found that Axl and Gas6 were highly expressed in surgically treated lung adenocarcinoma tissues at both genetic and protein levels, revealing their marked correlations with clinical outcomes. We believe that our findings contribute to further understanding of these promising molecules in utilizing them as novel biomarkers and therapeutic targets in NSCLC.

ACKNOWLEDGMENT We thank Ms. Seiko Sakai and Ms. Yuuka Taketani for their excellent administrative assistance. No outside funding was used for this project.

\section{CONFLICT OF INTEREST None declared.}

Open Access This article is distributed under the terms of the Creative Commons Attribution License which permits any use, distribution, and reproduction in any medium, provided the original author(s) and the source are credited.

\section{REFERENCES}

1. Parkin DM, Bray F, Ferlay J, Pisani P. Global cancer statistics, 2002. CA Cancer J Clin. 2005;55(2):74-108.

2. Alberg AJ, Samet JM. Epidemiology of lung cancer. Chest. 2003;123(1 Suppl):21S-49S.

3. Cascone T, Morelli MP, Ciardiello F. Small molecule epidermal growth factor receptor (EGFR) tyrosine kinase inhibitors in nonsmall cell lung cancer. Ann Oncol. 2006;17(Suppl 2):ii46-8.

4. Shaw AT, Yeap BY, Solomon BJ, et al. Effect of crizotinib on overall survival in patients with advanced non-small-cell lung cancer harbouring ALK gene rearrangement: a retrospective analysis. Lancet Oncol. 2011;12(11):1004-12. 
5. Linger RM, Keating AK, Earp HS, Graham DK. TAM receptor tyrosine kinases: biologic functions, signaling, and potential therapeutic targeting in human cancer. Adv Cancer Res. 2008;100:35-83.

6. O’Bryan JP, Frye RA, Cogswell PC, et al. Axl, a transforming gene isolated from primary human myeloid leukemia cells, encodes a novel receptor tyrosine kinase. Mol Cell Biol. 1991; 11(10):5016-31.

7. Sun W, Fujimoto J, Tamaya T. Coexpression of Gas6/Axl in human ovarian cancers. Oncology. 2004;66(6):450-7.

8. Green J, Ikram M, Vyas J, et al. Overexpression of the Axl tyrosine kinase receptor in cutaneous SCC-derived cell lines and tumours. Br J Cancer. 2006;94(10):1446-51.

9. Ou WB, Corson JM, Flynn DL, et al. AXL regulates mesothelioma proliferation and invasiveness. Oncogene. 2011;30(14): $1643-52$.

10. Gustafsson A, Martuszewska D, Johansson M, Ekman C, Hafizi S, Ljungberg B, Dahlback B. Differential expression of Axl and Gas6 in renal cell carcinoma reflecting tumor advancement and survival. Clin Cancer Res. 2009;15(14):4742-9.

11. Hutterer M, Knyazev P, Abate A, et al. Axl and growth arrestspecific gene 6 are frequently overexpressed in human gliomas and predict poor prognosis in patients with glioblastoma multiforme. Clin Cancer Res. 2008;14(1):130-8.

12. Varnum BC, Young C, Elliott G, et al. Axl receptor tyrosine kinase stimulated by the vitamin K-dependent protein encoded by growth-arrest-specific gene 6. Nature. 1995;373(6515):623-6.

13. Linger RM, Keating AK, Earp HS, Graham DK. Taking aim at Mer and Axl receptor tyrosine kinases as novel therapeutic targets in solid tumors. Expert Opin Ther Targets. 2010;14(10):1073-90.

14. Holland SJ, Powell MJ, Franci C, et al. Multiple roles for the receptor tyrosine kinase axl in tumor formation. Cancer Res. 2005;65(20):9294-303.

15. Hafizi S, Dahlback B. Signalling and functional diversity within the Axl subfamily of receptor tyrosine kinases. Cytokine Growth Factor Rev. 2006;17(4):295-304.

16. Wimmel A, Glitz D, Kraus A, Roeder J, Schuermann M. Axl receptor tyrosine kinase expression in human lung cancer cell lines correlates with cellular adhesion. Eur J Cancer. 2001; 37(17):2264-74.

17. Shieh YS, Lai CY, Kao YR, Shiah SG, Chu YW, Lee HS, Wu $\mathrm{CW}$. Expression of axl in lung adenocarcinoma and correlation with tumor progression. Neoplasia. 2005;7(12):1058-64.
18. Sobin L, Gospodarowicz M, Wittekind C. TNM classification of malignant tumours (UICC International Union Against Cancer). 7th edn. Oxford: Wiley-Blackwell Co., 2009.

19. Travis WD, Brambilla E, Muller-Hermelink HK, Harris CC. Pathology \& genetics of tumours of the lung, pleura, thymus and heart (World Health Organization Classification of Tumours). Vol 10. Lyon: IARC Press, 2004.

20. Sonobe M, Manabe T, Wada H, Tanaka F. Mutations in the epidermal growth factor receptor gene are linked to smokingindependent, lung adenocarcinoma. Br J Cancer. 2005;93(3): 355-63.

21. Tai KY, Shieh YS, Lee CS, Shiah SG, Wu CW. Axl promotes cell invasion by inducing MMP-9 activity through activation of NF-kappaB and Brg-1. Oncogene. 2008;27(29):4044-55.

22. Gjerdrum C, Tiron C, Hoiby T, et al. Axl is an essential epithelial-to-mesenchymal transition-induced regulator of breast cancer metastasis and patient survival. Proc Natl Acad Sci USA. 2010;107(3):1124-9.

23. Fridell YW, Jin Y, Quilliam LA, et al. Differential activation of the Ras/extracellular-signal-regulated protein kinase pathway is responsible for the biological consequences induced by the Axl receptor tyrosine kinase. Mol Cell Biol. 1996;16(1):135-45.

24. Ye X, Li Y, Stawicki S, et al. An anti-Axl monoclonal antibody attenuates xenograft tumor growth and enhances the effect of multiple anticancer therapies. Oncogene. 2010;29(38):5254-64.

25. Salgia R, Skarin AT. Molecular abnormalities in lung cancer. J Clin Oncol. 1998;16(3):1207-17.

26. Hasanbasic I, Cuerquis J, Varnum B, Blostein MD. Intracellular signaling pathways involved in Gas6-Axl-mediated survival of endothelial cells. Am J Physiol Heart Circ Physiol. 2004;287(3): H1207-13.

27. Mc Cormack O, Chung WY, Fitzpatrick P, et al. Growth arrestspecific gene 6 expression in human breast cancer. Br J Cancer. 2008;98(6):1141-6.

28. Loges S, Schmidt T, Tjwa M, et al. Malignant cells fuel tumor growth by educating infiltrating leukocytes to produce the mitogen Gas6. Blood. 2010;115(11):2264-73.

29. Stommel JM, Kimmelman AC, Ying H, et al. Coactivation of receptor tyrosine kinases affects the response of tumor cells to targeted therapies. Science. 2007;318(5848):287-90.

30. Eder JP, Shapiro GI, Appleman LJ, et al. A phase I study of foretinib, a multi-targeted inhibitor of c-Met and vascular endothelial growth factor receptor 2. Clin Cancer Res. 16(13):3507-16. 